\title{
Artificial ageing of Silane Terminated Polymer adhesive for façade application
}

\author{
Markéta Zikmundová ${ }^{1}$, Klára V. Machalická2 ${ }^{2}$ Martina Eliášová ${ }^{3}$, Miroslav Vokáć ${ }^{4}$ \\ ${ }^{1,3}$ Department of Steel and Timber Structures, Faculty of Civil Engineering, \\ Czech Technical University in Prague, Prague, Czech Republic \\ ${ }^{2,}{ }^{4}$ Klokner Institute, Czech Technical University in Prague, Prague, Czech Republic \\ E-mail: ${ }^{1}$ marketa.zikmundova@fsv.cvut.cz (corresponding author)
}

\begin{abstract}
Adhesive bonding is commonly used in the automotive and aerospace industry, where it has proved its advantages. Nowadays, the bonded joints are starting increasingly used in civil engineering, where they can be applied in façade structure. Traditionally used structural silicones are resistant to the external environment, but their low strength and elasticity do not meet the requirements of civil engineering. The greater spread of higher strength adhesives such as acrylates or polyurethanes is hampered by the lack of knowledge of their ageing resistance.

The paper is focused on the experimental analysis of a double-lap shear joints of Silane Terminated Polymer (STP) adhesive applied in joints with aluminium and $\mathrm{Zn}$-electroplated steel substrates with various surface treatments. The specimens were exposed to artificial ageing according to the technical regulations of the Timber Research and Development Institute in Prague. According to this regulation, specimens were exposed to changing of high and low temperatures, UV-radiation and humidity. This ageing should simulate 5 years in the climatic environment of Central Europe. Specimens exposed to laboratory ageing are compared with reference set of test specimens that were not artificially aged. STP demonstrated excellent resistance to laboratory ageing.
\end{abstract}

Keywords: adhesive, façade applications, artificial ageing, metal substrate, double lap shear.

\section{Introduction}

Screwed joint weakens cross-section of the bonded material and causes stress concentration in connection. In the case of welded joints, residual stresses and deformations from heating are generated in the joined material. Adhesive bonding eliminates these problems. Adhesively bonded joints eliminate these problems because the stress is distributed uniformly along the bonded joint, depending on the stiffness of the applied adhesive, the cross section is not weakened by the holes, they have visually smooth surface and they can connect different material as glass, steel, wood etc.

Silicones have been used in civil engineering for decades, especially for glass facades and different kind of glazing. Silicones are resistant to ageing, but relatively low strength and stiffness do not meet current requirements for their application on facades. Therefore, adhesives with higher strength and stiffness are required. Standards used in the automotive and aerospace industries cannot be used directly for the application of these adhesives in civil engineering, because of the different requirements on durability, strict geometrical imperfections etc. Adhesive bonding used for façade applications is exposed to the external environment, such as high and low temperature, humidity and UV radiation that affect mechanical properties of the bonded joint.

The issue of ageing adhesive joints is solved in a number of research centres. The following chapter gives examples of adhesive application in façade and research aimed at verification of adhesive mechanical properties exposed to artificial ageing. The next part of the paper describes experimental research focused on artificial ageing of silane terminated polymer, which was performed in the Klokner Institute in cooperation with the Faculty of Civil Engineering, CTU in Prague

\section{Adhesive application in façade}

German research team FABIG develops bioenergy building skin, which is made of glass hollow panels where liquid culture medium is in glazing cavity. Microalgae grow in the liquid medium and produced biomass, heat and energy. When the algae are harvested, they can be used in the food or pharmaceutical industries for their containing of vitamins, enzymes, antioxidants and omega-3 fatty acids. Bioenergy panels can be also used as a shading device. 
The photo-bioreactor panels measure $1.35 \times 3.0 \mathrm{~m}$. Front and back glazing consist of laminated safety glass panes that create an inner cavity of $10 \mathrm{~mm}$. The inner part of the panel is divided into 4 parts, see Figure 1 . The adhesive is used for joints of the outer and inner parts of the panel. Four adhesives (silicone, polyurethane, epoxy and hybrid) were tested to mechanical properties and resistance to ageing. (Aßmus, Popp, \& Weller, 2018).

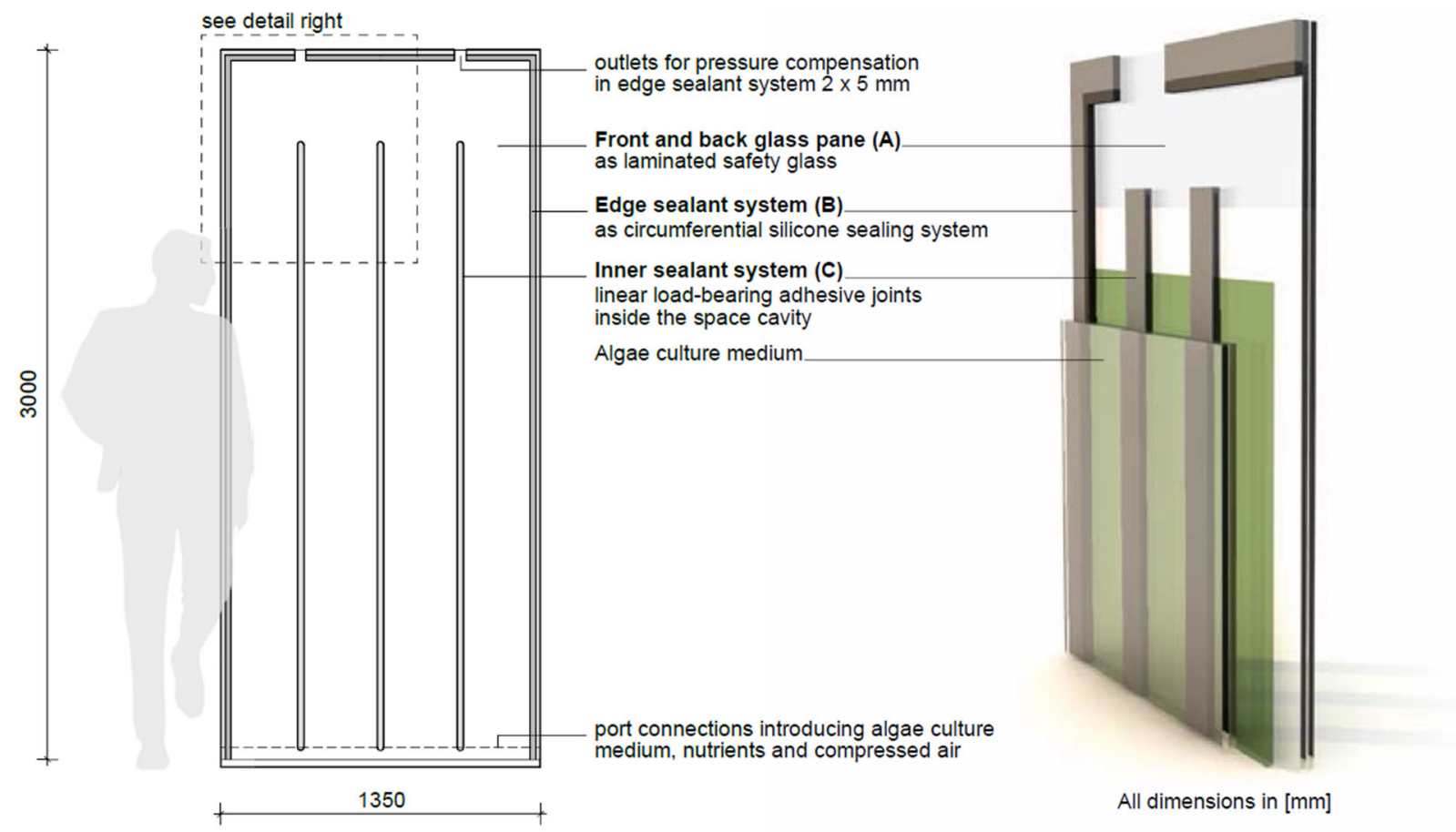

Figure 1. Component of photobioreactor (Aßmus et al., 2018)

Timber is natural and renewable material which is modern again and is used for building elements. The University of Dresden is working on a load-bearing timber-glass composite façade panel where glass is not only applied as infill material. The glass panes are circumferentially adhesively bonded to the wooden frame, see Figure 2, with silicone. Silicone is flexible adhesive and allows large deformations of the joint. For this reason, adhesives with medium or high stiffness are better for load-bearing applications. The research team at the University of Dresden tested semi-rigid adhesive (Silane terminated polymer/epoxy) and rigid adhesive (Epoxy) (Nicklisch \& Weller, 2016)

\section{Experimental testing of adhesive connection durability}

Experimental analysis focused on durability of bonded joints were made for mentioned bioenergy facade project. Specimens were prepared according to ETAG 002 and EN ISO 13022. Four adhesives (silicone, polyurethane, epoxy and hybrid) were selected for testing. The influence of temperature and the effect of different liquids on ageing of test specimens were investigated. The mechanical properties of the bonded joint were tested at $-20{ }^{\circ} \mathrm{C},+35^{\circ} \mathrm{C}$ and $+80{ }^{\circ} \mathrm{C}$ for $24 \mathrm{~h}$. The test specimens were stored for 21 days in water, acid solution, base solution and hydrogen peroxide solution and were immediately tested after removal from liquids. Specimens were tested in tensile strength. All adhesives showed excellent temperature resistance. However, the ageing resistance of adhesives was not so good. The test results were evaluated according to EN 15434. Silicone was able to meet the standard criteria only. Polyurethane met the standard criteria for all solutions except for hydrogen peroxide. Epoxy and hybrid adhesives showed good and fair ageing resistance. For further research, silicone was selected (the only one met all standard conditions) and the epoxy which achieves high tensile strengths after ageing. (Aßmus et al., 2018)

Project aimed at wood-glass composite material also tested ageing resistance of adhesives connection. Two substrates (birch plywood and pine wood) and three different adhesives (silicone, semi-rigid silane terminated polymer (STM) with epoxy and rigid epoxy) were selected. Silicone was tested only in reference set. Two shapes of specimens according to ETAG 002-1 were used - for tensile and shear tests. A total of 600 specimens were tested. The experimental programme had three stages: first, tensile and shear test at room temperature; second, tensile and shear test at $-20^{\circ} \mathrm{C}$ and $+80^{\circ} \mathrm{C}$; third, tensile and shear test after ageing. Four ageing scenarios according to guideline iftVE08/2 were chosen - UV-exposure, immersion in cleaning agent solution, wetting/drying and $\mathrm{SO}_{2}$-exposure. The semi-rigid adhesive exhibited good ageing resistance except from UV-exposed specimens where the strength of the reference set to aged bodies decreased on 35\%. On the other hand, epoxy achieved good results after exposure to UV-light, but exposure to cleaning solution greatly reduced its strength. Semi-rigid adhesives and rigid adhesives can 
only be recommended if redundant compensatory measures are taken or the joint is protected against critical environmental influences (e.g. covering of semi-rigid adhesive with non-transparent material) (Nicklisch \& Weller, 2016).

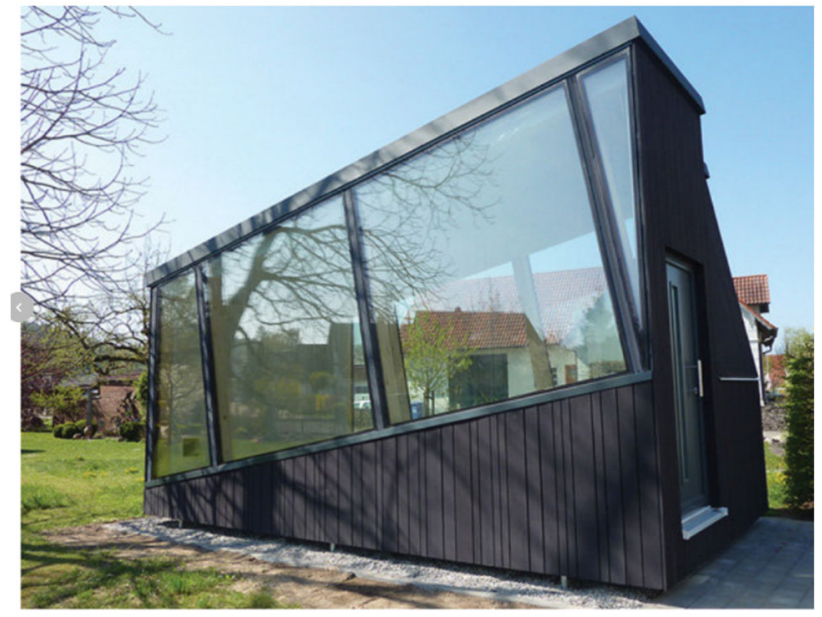

Figure 2a. Pilot project of timber-glass composite shear wall (Nicklisch \& Weller, 2016)

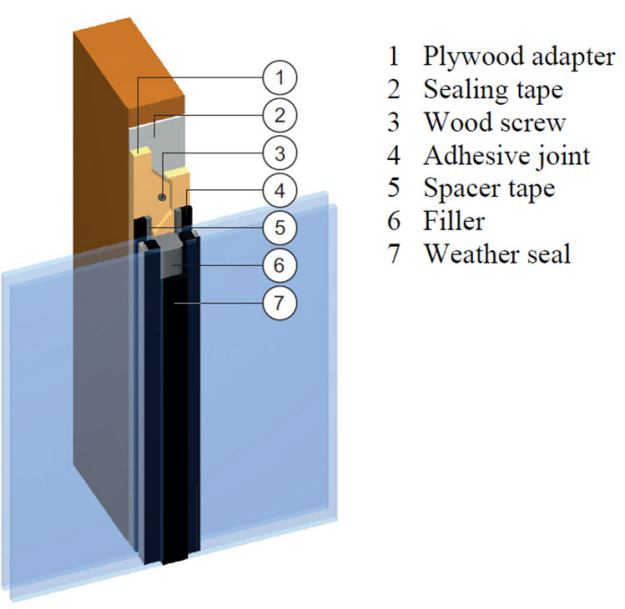

Figure 2b. Timber-glass composite facade by UNIGLAS ) (Nicklisch \& Weller, 2016)

Above mentioned examples showed potential in adhesive bonding especially in façade application. Glass is used in both, but it is also possible to use another material (Liška, Šlanhof, \& Nečasová, 2014; Liška, Šlanhof, Nečasová, \& Kovářová, 2016). The next chapter describes research focused on adhesive bonding of various metals (aluminium, anodized aluminium, Zn-electroplated steel) with the influence of artificial ageing combining moisture, UV radiation, high and low temperatures.

\section{Experimental programme}

The experimental study contained two batches of specimens - reference set and specimens exposed to laboratory ageing according to the technical regulation of the Timber Research and Development Institute in Prague. Experiments were carried out in the laboratory of the Klokner Institute, CTU in Prague.

\section{Substrates and adhesive}

Five different substrates were used for the specimens: Zn-electroplated steel, aluminium and anodized aluminium with smooth surface and Zn-electroplated steel and aluminium with mechanically roughened surface of bonded area. A silane terminated polymer (STP), a gap-filling elastomer, a silicone-polyurethane hybrid was used as adhesive bond. The curing process is based on a chemical reaction with atmospheric humidity.

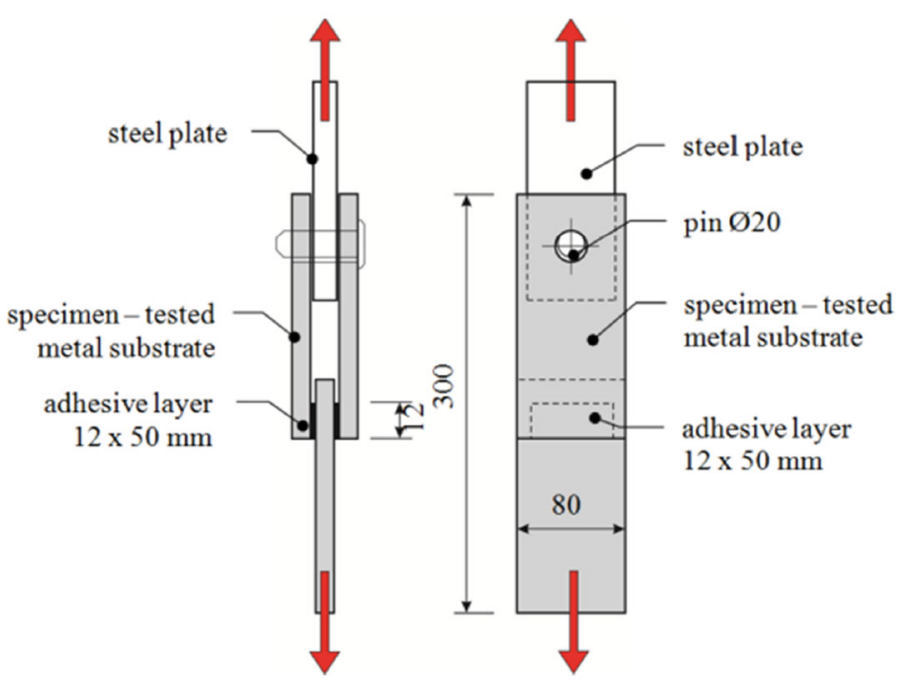

Figure 3a. Scheme of double lap shear specimen

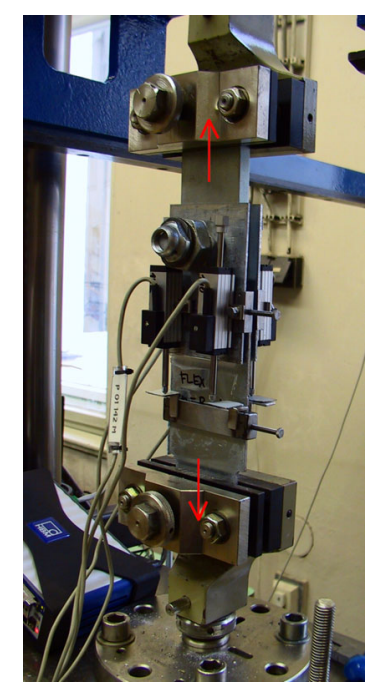

Figure 3b. Test set-up 


\section{Specimen geometry}

The test specimens were prepared as double lap shear joint see Figure 3. The size of the bonded area was $12 \times 50 \mathrm{~mm}$ and the joint thickness was $4.8 \mathrm{~mm}$. Each set of specimens with the same substrate contained 5 specimens, thus a total of 25 aged specimens and 25 unaged specimens were tested. Bonded area was cleaned, degreased and activated with pre-treatment agent to ensure better adhesion.

The specimens were subjected to displacement controlled test in TIRA TEST machine, where shear loading of bonded area arose from tensile loading of the whole specimen, Figure 3a, 3b. The test specimens were loaded at a crosshead speed of $5 \mathrm{~mm} / \mathrm{min}$. Loading was introduced continuously until the total failure of the joint. Displacement was measured by two linear potentiometric transducers at both ends of one overlap joint, therefore, four transducers per one specimen were used.

\section{Artificial ageing}

The specimens were exposed to laboratory ageing according to the technical regulation of the Timber Research and Development Institute in Prague. This regulation was originally developed for polymer coatings and it can be used for other polymers. The regulation was firstly used for artificial ageing procedure of adhesive joints at CTU in Prague for metal-to-glass and glass-to-glass connections bonded by polyurethane and acrylate adhesives (Machalická \& Eliášová, 2013). Basic cycle of artificial ageing is shown in Figure 4. Specimens are initially exposed to $20^{\circ} \mathrm{C}$ for 8 hours, then cooled to $-20^{\circ} \mathrm{C}$ for 16 hours, after which the temperature is returned to $20{ }^{\circ} \mathrm{C}$ for 8 hours and then the specimens are exposed to $+80{ }^{\circ} \mathrm{C}$ for 16 hours. In $20^{\circ} \mathrm{C}$ temperature periods, specimens were subjected to alternating demineralized water showers and UV-radiation exposure every 20 minutes. This cycle was repeated twice. Subsequently, the specimens are conditioned for 64 hours at $20 \pm 2{ }^{\circ} \mathrm{C}$ and $60 \pm 5 \%$ humidity. The base cycle lasts 7 days. Whole cycle is repeated nine-times to obtain procedure which can replace 5 years in exterior conditions of Central Europe.

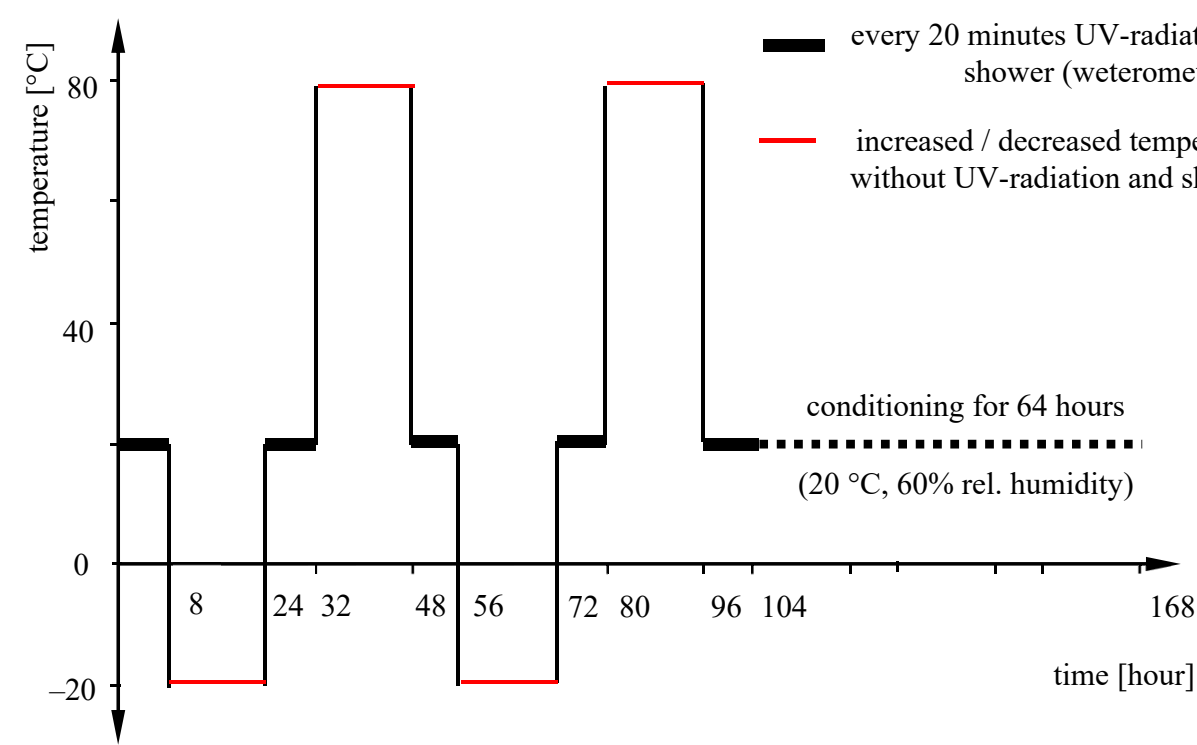

Figure 4. Artificial ageing typical cycle

Table 1. Average shear strength values and failure modes for STP adhesive, $\mathrm{C}$ - cohesive mode,

$\mathrm{A}$ - adhesive mode, A-C - combined mode, where letter in bold means prevailing mode of failure

\begin{tabular}{|c|c|c|c|c|c|}
\hline \multirow{2}{*}{ Type of specimen } & \multicolumn{2}{|c|}{ Reference set } & \multicolumn{2}{|c|}{ After ageing } & \multirow{2}{*}{$\begin{array}{l}\text { Strength } \\
\text { reduction }\end{array}$} \\
\hline & Strength $[\mathrm{MPa}]$ & Failure & Strength $[\mathrm{MPa}]$ & Failure & \\
\hline Roughened Aluminium & 1.87 & $\mathrm{C}$ & 1.68 & $\mathrm{~A}-\mathrm{C}$ & $9.81 \%$ \\
\hline Smooth Aluminium & 1.89 & $\mathrm{C}$ & 1.64 & $\mathrm{~A}-\mathrm{C}$ & $13.02 \%$ \\
\hline Anodized Aluminium & 1.87 & $\mathrm{C}$ & 1.71 & $\mathrm{~A}-\mathrm{C}$ & $8.61 \%$ \\
\hline Roughened Zn-electroplated steel & 1.69 & $\mathrm{C}$ & 1.60 & $\mathrm{~A}-\mathrm{C}$ & $5.62 \%$ \\
\hline Smooth Zn-electroplated steel & 1.72 & $\mathrm{C}$ & 1.67 & $\mathrm{~A}-\mathrm{C}$ & $2.91 \%$ \\
\hline
\end{tabular}




\section{Results}

The average shear strength of aged and non-aged specimens is shown in Table 1. Decreasing of the shear strength is evident in specimens after artificial ageing. However, this drop is maximum for smooth aluminium (13\%). The smallest decrease in strength occurred in smooth Zn-electroplated steel (2.91\%), Table 1. Specimens in reference set showed excellent adhesion to all substrates and only cohesive failure occurred. Specimens after laboratory ageing showed damage from moisture at the edges of the adhesive layer, see Figures $5 \mathrm{a}$ and $5 \mathrm{~b}$. However, the effect of moisture was only at the edge of the adhesive bond and the damage was defined as adhesively cohesive with the prevailing cohesive failure, Table 1.
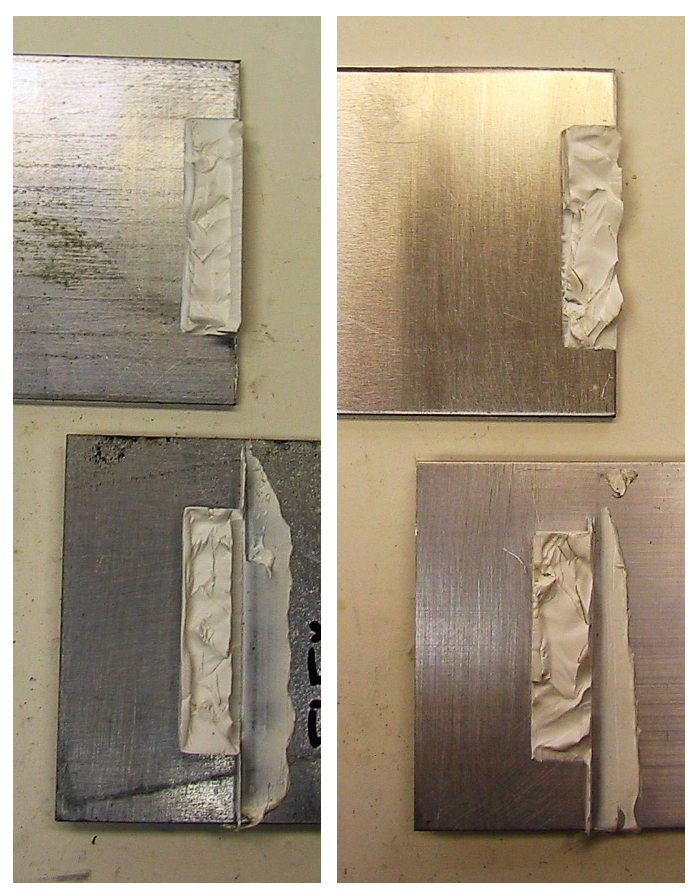

Figure 5a. Specimen from reference set after shear test, roughened $\mathrm{Zn}$-electroplated steel (left), roughened aluminium (right)
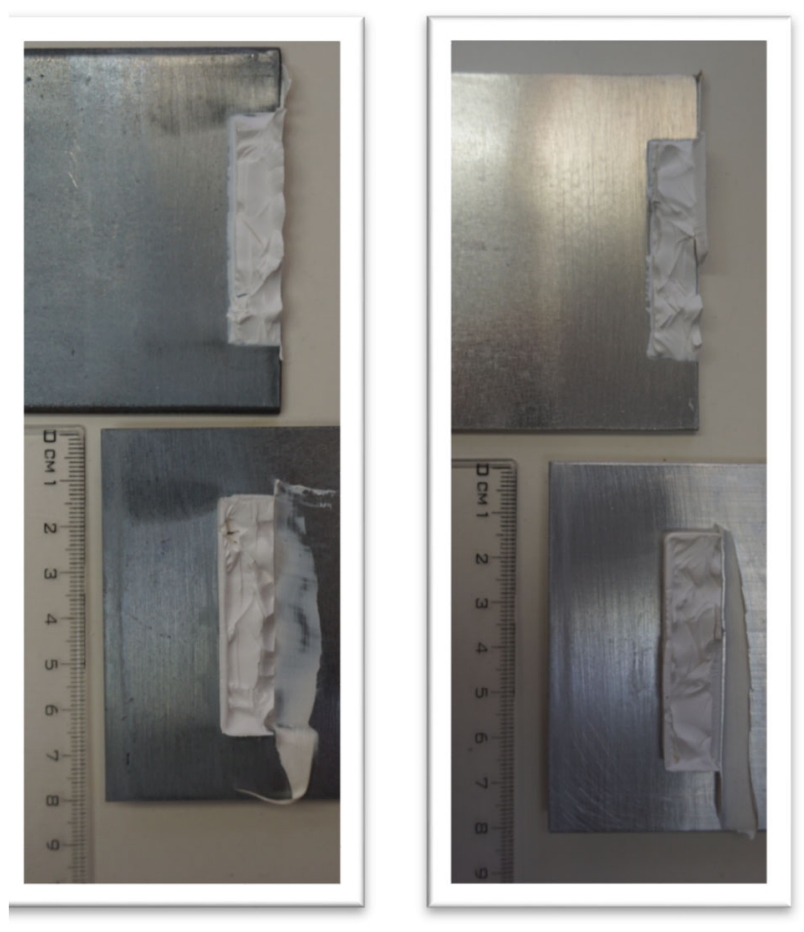

Figure $5 \mathrm{~b}$. Artificially aged specimen after shear test, roughened $\mathrm{Zn}$-electroplated steel (left), roughened aluminium (right)

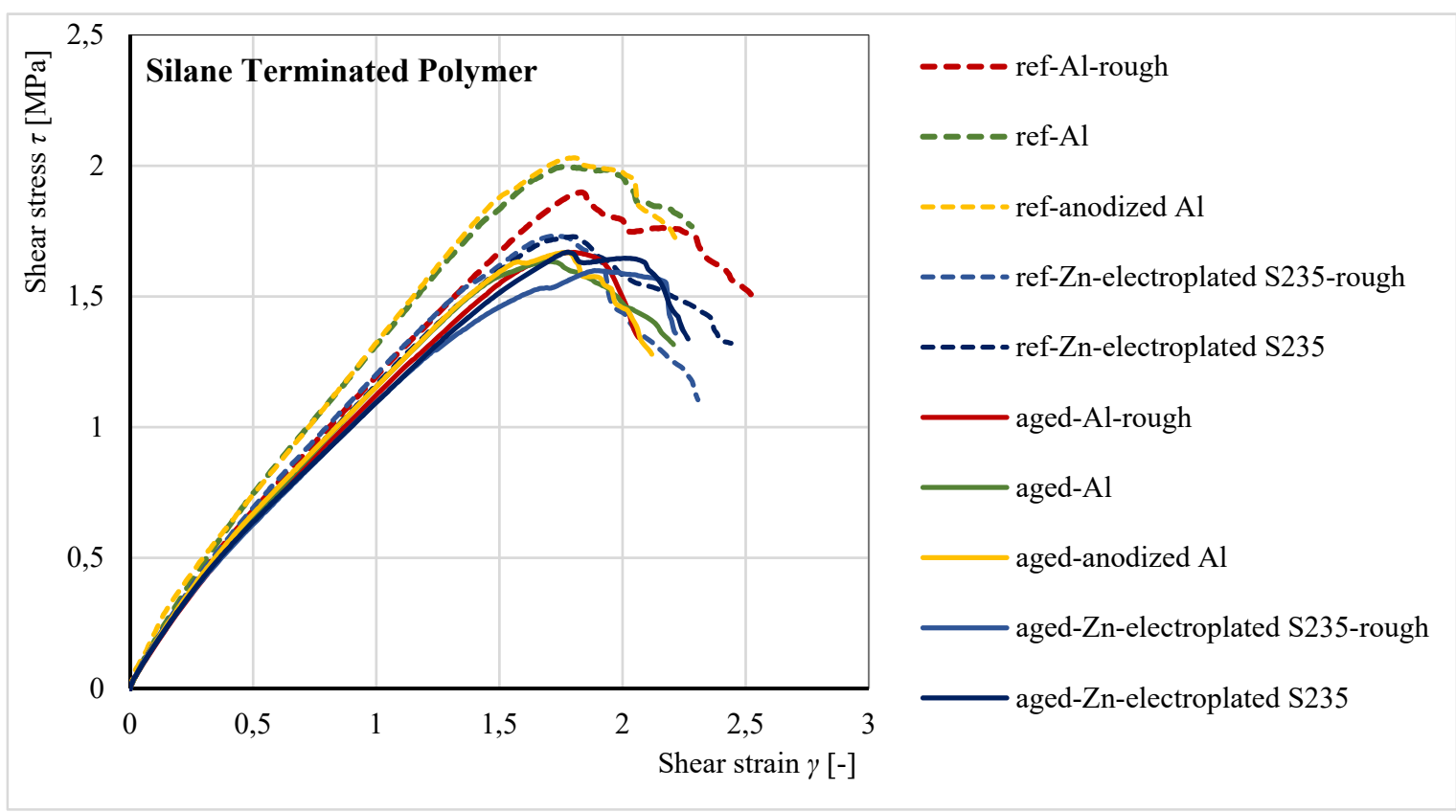

Figure 6. Stress-strain relationship for reference set of specimens and artificially aged specimens 
Figure 6 shows decrease in shear strength of aged specimens. There was also a slight decrease in the initial stiffness of the bonded joint. Surface treatment did not show any effect on shear strength or failure mode. However, it is evident from Figure 7 that for smooth aluminium is variance greater than for roughened aluminium. Shear strength of $\mathrm{Zn}$-electroplated steel specimens in the reference set was slightly lower than aluminium specimens, but the bonded joint on $\mathrm{Zn}$-electroplated steel was more resistant to laboratory ageing.

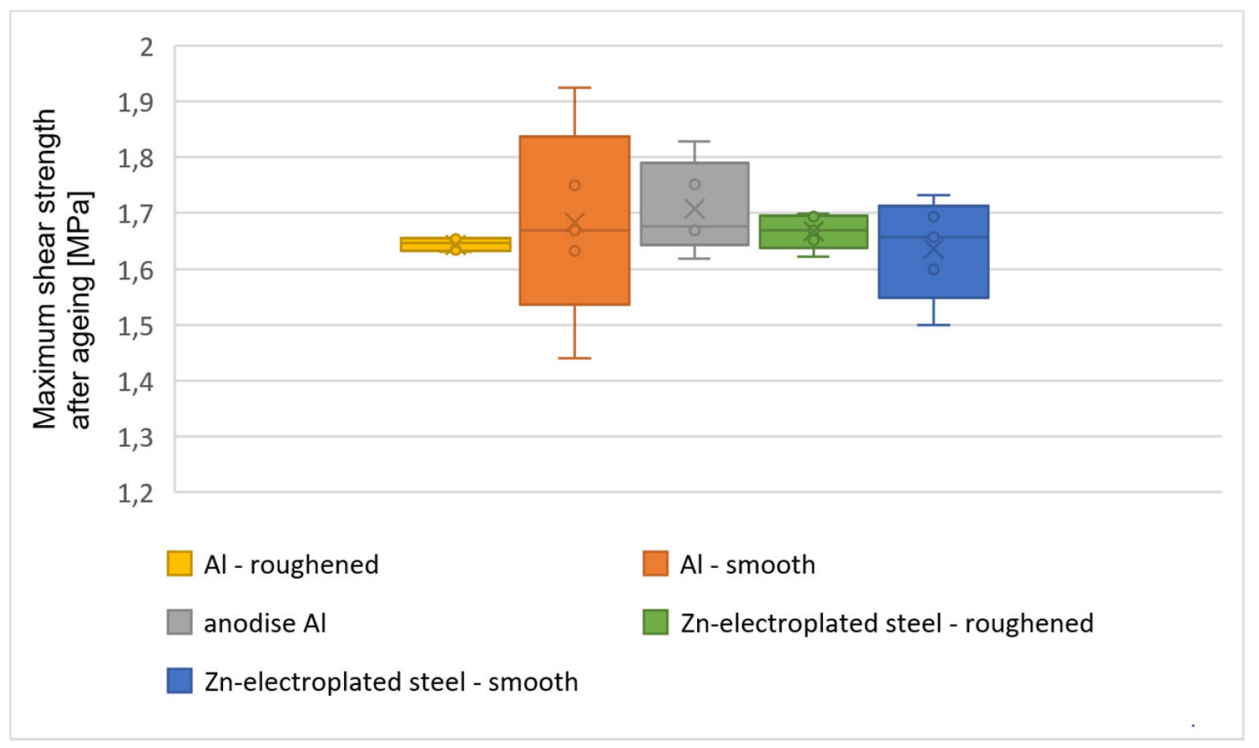

Figure 7. Maximum shear strength after laboratory ageing

\section{Conclusions}

Silane terminated polymer demonstrated excellent resistance to laboratory ageing. The differences in shear strength and failure mode are not affected by individual substrates or their surface treatment. Specimens after laboratory ageing showed corrosive effect of moisture which caused adhesion failure at the edge of the bonded joint. Selected laboratory ageing should simulate 5 years in exterior conditions of Central Europe. It would be useful to compare the test results of specimens exposed to artificial ageing with those of specimens that would be exposed to natural climatic conditions. This is the only way to verify the suitability of this method. It should also be noted that the influence of individual degradation effects has various impact on the strength with respect to the chemical composition of used adhesives.

\section{Acknowledgements}

This work was supported by the Czech Science Foundation [grant number GA18-10907S]; and the Student grant competition of CTU [grant number SGS18/169/OHK1/3T/11].

\section{References}

Aßmus, E., Popp, Ch., \& Weller, B. (2018, May). Permanent hydrothermal exposure on load-bearing adhesives in glass constructions. In Challenging Glass 6, Delft, The Netherlands. 10 p.

Liška, P., Šlanhof, J., \& Nečasová, B. (2014). Revitalization of façade cladding with the use of bonded joints. Advanced Materials Research, 1041, 191-194. https://doi.org/10.4028/www.scientific.net/AMR.1041.191

Liška, P., Šlanhof, J., Nečasová, B., \& Kovářová, B. (2016). Experimental investigation of tensile properties of ventilated façade cladding with bonded joints. Applies Mechanics and Materials, 824, 50-59. https://doi.org/10.4028/www.scientific.net/AMM.824.50

Machalická, K., \& Eliášová, M. (2013, July). Influence of various factors to mechanical properties of glued joint in glass. In $2^{\text {nd }}$ International Conference on Structures and Architecture (pp. 321-328). Guimaraes, Portugal.

Nicklisch, F., \& Weller, B. (2016, August). Adhesive bonding of timber and glass in load-bearing facades - evaluation of the ageing behaviour. In World Conference on Timber Engineering (WCTE 2016). Vienna, Austria. 8 p. 